\title{
Review
}

\section{Update to Evidence-Based Secondary Prevention Strategies After Acute Coronary Syndrome}

\author{
David H. Fitchett, MD, ${ }^{a}$ Lawrence A. Leiter, MD, ${ }^{a}$ Peter Lin, MD, ${ }^{b}$ Jennifer Pickering, BScPhm, ${ }^{c}$ \\ Robert Welsh, MD, ${ }^{\mathrm{d}}$ James Stone, PhD, MD, ${ }^{\mathrm{e}}$ Jean Gregoire, MD, ${ }^{\mathrm{f}}$ Philip McFarlane, PhD, MD, ${ }^{\mathrm{a}}$ \\ Anatoly Langer, MD, ${ }^{\mathrm{a}, \mathrm{b}}$ Anil Gupta, MD, ${ }^{\mathrm{g}}$ and Shaun G. Goodman, MD, MSc ${ }^{\mathrm{a}, \mathrm{b}, \mathrm{d}}$ \\ a St Michael's Hospital, University of Toronto, Toronto, Ontario, Canada \\ ${ }^{b}$ Canadian Heart Research Center, Toronto, Ontario, Canada \\ ${ }^{c}$ Hamilton Heath Sciences, Hamilton, Ontario, Canada \\ ${ }^{d}$ Canadian VIGOUR Centre, University of Alberta and Mazankowski Alberta Heart Institute, Edmonton, Alberta, Canada \\ 'University of Calgary, Calgary, Alberta, Canada \\ ${ }^{f}$ Montreal Heart Centre, University of Montreal, Montreal, Quebec, Canada \\ ${ }^{g}$ Trillium Health Partners, Mississauga, Ontario, Canada
}

\begin{abstract}
A recent acute coronary syndrome provides an opportunity to optimise secondary prevention strategies to reduce the risk of future cardiovascular events. This review provides an updated synopsis of current evidence-based approaches. New clinical trial data on the use of antiplatelet and anticoagulants allow choices of the selection and duration of treatment. Lipid lowering after an acute coronary syndrome is now enhanced, with proprotein convertase subtilisin-kexin type 9 inhibitors providing added benefit on top of statin and ezetimibe treatment in high-risk patients. In addition, a recent trial of icosapent ethyl, a highly purified ethyl ester of eicosapentaenoic acid, addresses residual risk in patients with elevated triglycerides already treated with
\end{abstract}

In 2016, our review of strategies for evidence-based secondary prevention of cardiovascular events after acute coronary syndrome (ACS) was published. ${ }^{1}$ We now update these approaches based on information that has since become available. This update has a similar approach to the original review and is not intended to be a new clinical practice guideline or designed to be a systematic review. The goal is to provide a platform for discussion about the role of new treatments in secondary prevention after an ACS.

Received for publication February 25, 2020. Accepted April 3, 2020.

Ethics Statement: This is a review and all the studies and all the studies quoted has adhered to relevant ethical guidelines.

Corresponding author: Dr David Fitchett, Division of Cardiology, St Michael's Hospital, 30 Bond St, Toronto, Ontario M5B 1W8, Canada.

E-mail: fitchett.david.h@gmail.com

See page 412 for disclosure information.

\section{RÉSUMÉ}

La survenue récente d'un syndrome coronarien aigu offre l'occasion d'optimiser les stratégies de prévention secondaire en vue de réduire le risque d'événements cardiovasculaires futurs. Le présent article de synthèse offre une vue d'ensemble actualisée des approches contemporaines fondées sur des données probantes. Les nouvelles données d'essais cliniques sur l'utilisation d'antiplaquettaires et d'anticoagulants permettent de choisir un traitement et sa durée. La réduction des lipides après la survenue d'un syndrome coronarien aigu se trouve maintenant améliorée, les bienfaits des inhibiteurs de la proprotéine convertase subtilisine/kexine de type 9 s'ajoutant à ceux du traitement par des statines et l'ézétimibe chez les patients à haut
Most of the secondary prevention strategies in the original algorithm are unchanged. However, new data support the use of (1) oral antithrombotic therapy in addition to, or instead of, acetylsalicylic acid (ASA) in high-risk patients after ACS; (2) proprotein convertase subtilisin-kexin type 9 (PCSK9) inhibitors; (3) icosapent ethyl (EPA); and (4) glucose-lowering agents with cardiovascular benefit in patients with type 2 diabetes mellitus.

Figure 1 shows the original strategies described in 2016 for secondary prevention and highlights the updated/new features in bold type. The algorithm continues to stress the need for lifestyle and cardiovascular disease (CVD) risk factor management, including referral to a cardiac rehabilitation program.

\section{Oral Antithrombotic Therapy in Addition to or Instead of ASA}

Dual oral antiplatelet therapy during and after ACS was established after the Clopidogrel in Unstable Angina to 
statins. The use of both sodium-glucose co-transporter 2 inhibitors and glucagon-like peptide-1 receptor agonists in patients with type 2 diabetes reduces cardiovascular events independently of glucose lowering.

Prevent Recurrent Ischemic Events (CURE) trial ${ }^{2}$ with the superiority of ASA and clopidogrel compared with ASA alone. Subsequently, both ticagrelor ${ }^{3}$ and prasugrel $^{4}$ were shown to be superior to clopidogrel. The open label Intracoronary Stenting and Antithrombotic Regimen: Rapid Early Action for Coronary Treatment 5 (ISAR REACT 5) study showed potential outcome advantages for prasugrel compared with ticagrelor. However, because prasugrel will not be available in the near future, the standard of care for dual antiplatelet therapy (DAPT) after ACS has become ASA plus ticagrelor for 1 year. Furthermore, the increased bleeding rates associated with DAPT have led to a search for alternative strategies (Table 1).

A number of recent trials have assessed the potential for shorter duration (eg, 1 or 6 months vs 12 months) of DAPT, including in patients with ACS. ${ }^{5,6}$ However, these open-label, noninferiority design trials, although showing reduced risk of bleeding with shorter vs 1-year duration of DAPT (most commonly using clopidogrel), have also demonstrated numeric (or statistically significant) increases in ischemic events, including reinfarction and stent thrombosis. Thus, unless the patient is at particularly high risk for bleeding, ticagrelor or prasugrel (in preference to clopidogrel) should be used for at least 1 year after ACS/percutaneous coronary intervention (PCI), as per the Canadian Cardiovascular Society Antiplatelet Guideline recommendations.?

The Ticagrelor Plus Aspirin Followed by Ticagarelor Monotherapy vs a Current-Day Intensive Dual Antiplatelet Therapy in Patients Undergoing Percutaneous Coronary Intervention With Bivalirudin and Biomatrix Family DrugEluting Stents (GLOBAL LEADERS), ${ }^{8}$ Smart Angioplasty Research Team: Comparison Between P2Y12 Antagonist Monotherapy vs Dual Antiplatelet Therapy in Patients Undergoing Implantation of Coronary Drug-Eluting Stents (SMART-CHOICE), ${ }^{9}$ and Ticagrelor With Aspirin or Alone in High-Risk Patients After Coronary Intervention (TWILIGHT) ${ }^{10}$ trials have examined the potential for reducing bleeding by using $\mathrm{P}_{2} \mathrm{Y}_{12}$ receptor inhibitor monotherapy vs DAPT after PCI, including in patients after ACS. ${ }^{8,10,11}$ These studies show that after an initial period of DAPT, patients post-PCI, including those with ACS, could be considered for $\mathrm{P}_{2} \mathrm{Y}_{12}$ inhibitor monotherapy, particularly in patients at high bleeding risk. However, not all of these trials were adequately powered to assess ischemic outcomes post-ACS.

Since the 2016 recommendation for consideration of extension of DAPT with a $\mathrm{P}_{2} \mathrm{Y}_{12}$ receptor inhibitor and ASA in those patients vascular disease who tolerated (without significant bleeding) these and were adherent to DAPT from the index ACS to approximately 1 year, additional clinical trials such as Prevention of Cardiovascular risque. En outre, un essai récent portant sur l'icosapent éthyl, un ester éthylique hautement purifié de l'acide eicosapentaénoïque, aborde le risque résiduel chez les patients présentant une hypertriglycéridémie déjà traités par des statines. L'utilisation d'inhibiteurs du cotransporteur sodium-glucose de type 2 et d'agonistes des récepteurs du peptide-1 apparenté au glucagon chez les patients atteints de diabète de type 2 limite les événements cardiovasculaires indépendamment de la diminution de la glycémie.

Events in Patients With Prior Heart Attack Using Ticagrelor Tablets Compared to Placebo on a Background of AspirinThrombolysis in Myocardial Infarction 54 (PEGASUSTIMI 54) ${ }^{12}$ trial give continued support for this approach. Subgroup analyses from the PEGASUS-TIMI 54) $\mathrm{trial}^{13}$ have identified particularly high-risk patients after MI who derive large absolute benefit of ticagrelor $60 \mathrm{mg}$ twice daily added to ASA vs ASA alone. Those with diabetes, chronic kidney disease (ie, estimated glomerular filtration rate [eGFR] $<60 \mathrm{~mL} / \mathrm{min} / 1.73 \mathrm{~m}^{2}$ ), ${ }^{14}$ peripheral artery disease (PAD), ${ }^{15}$ and multivessel coronary artery disease (CAD), ${ }^{16}$ all derived important outcome benefits with ticagrelor compared with placebo. In most subgroups, the incremental major bleeding risk observed with ticagrelor was similar in relative terms to that seen in the overall trial population when compared with ASA alone.

A prospective economic substudy of the PEGASUSTIMI 54 trial (assessed from a US healthcare system perspective with typically higher drug and hospitalization costs) identified several high-risk subgroups, including patients with $>1$ prior MI, multivessel disease, diabetes, and renal dysfunction, and particularly those aged $<75$ years and those with PAD, in whom the incremental costeffectiveness ratio was comparable to several other secondary prevention approaches currently used in clinical practice. ${ }^{17}$ Despite this evidence for cost-effectiveness, there is a lack of Canadian provincial formulary approval of extended ticagrelor use (beyond the first year).

\section{Oral Anticoagulation Therapy}

The Cardiovascular Outcomes for People Using Anticoagulation Strategies (COMPASS) trial randomly assigned 27,395 participants with chronic atherosclerotic cardiovascular disease (ASCVD) (CAD or PAD, including those with carotid artery disease) to receive rivaroxaban $(2.5 \mathrm{mg}$ twice daily) plus ASA (100 mg once daily), rivaroxaban (5 mg twice daily), or ASA (100 mg once daily) in a double-blind fashion. ${ }^{18}$ Details of the study are shown in Table 2 .

The primary outcome of a composite of cardiovascular (CV) death, stroke, or MI (mean follow-up 23 months) occurred in significantly fewer patients in the rivaroxaban 2.5 $\mathrm{mg}$ twice daily plus ASA group than in the ASA alone group (4.1\% vs $5.4 \%$; hazard ratio [HR], 0.76; $95 \%$ confidence interval $[\mathrm{CI}], 0.66-0.86 ; P<0.001) .{ }^{18} \mathrm{CV}$ death was reduced $22 \%$, as was all-cause mortality $18 \%$ and stroke $42 \% .{ }^{19}$ Although major bleeding events $(\sim 50 \%$ of which were gastrointestinal) occurred in more patients in the rivaroxaban plus ASA group (3.1\% vs 1.9\%; HR, 1.70 [1.40-2.05]; $P<$ $0.001)$, there was no significant difference in intracranial or 


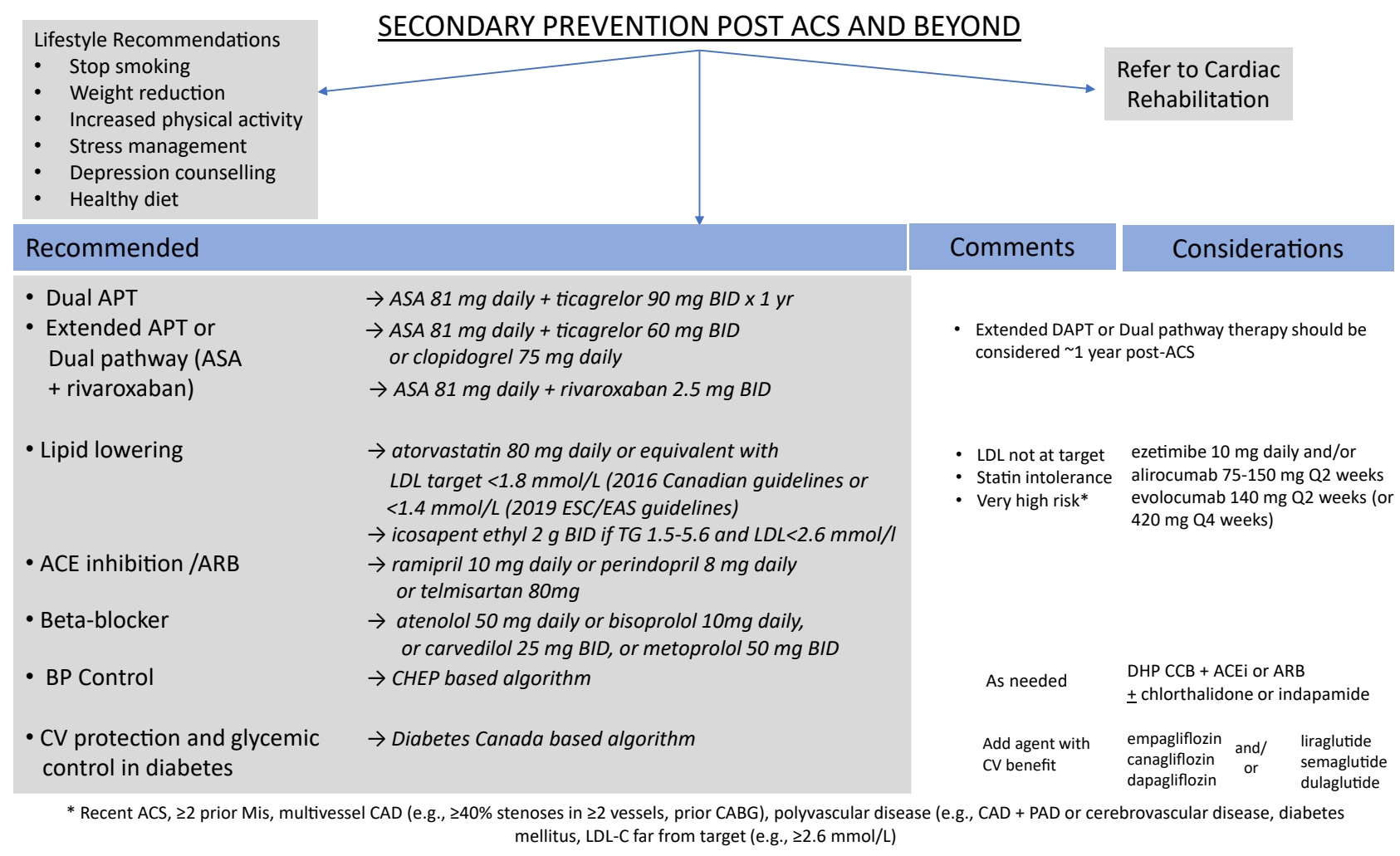

Figure 1. Algorithm for the secondary prevention of cardiovascular events in patients with recent acute coronary syndrome (ACS). ACE, angiotensinconverting enzyme; ACEi, angiotensin-converting enzyme inhibitor; APT, antiplatelet therapy; ARB, angiotensin receptor blocker; ASA, acetylsalicylic acid; BID, twice per day; BP, blood pressure; CABG, coronary artery bypass grafting; CAD, coronary artery disease; CHEP, Canadian Hypertension Education Program; CV, cardiovascular; DAPT, dual antiplatelet therapy; DHP CCD, dihydropyridine calcium channel blocker; EAS, European Atherosclerosis Society; ESC, European Society of Cardiology; LDL, low-density lipoprotein; PAD, peripheral artery disease; TG, triglyceride.

fatal bleeding between these 2 groups. Further, the net clinical benefit over time (eg, absolute risk differences for major adverse cardiovascular events compared with fatal bleeding or symptomatic bleeding into a critical organ) was highlighted in a recent COMPASS analysis that concluded that most excess bleeding occurred during the first year after randomization, was of mild or moderate intensity, and was managed with conventional supportive therapy. ${ }^{20}$ In contrast, there was no primary outcome benefit in the rivaroxaban-alone compared with the ASA-alone group, and major bleeding events occurred more frequently in the rivaroxaban-alone group.

Major adverse limb events (severe limb ischemia leading to an intervention [angioplasty, bypass surgery, amputation, thrombolysis] or major amputation above forefoot due to vascular cause) also occurred significantly less frequently in those receiving rivaroxaban plus ASA compared with ASAalone $(1 \%$ vs $2 \%$; HR, 0.54 [0.35-0.82]; $P=0.004)$, including those with $\mathrm{CAD}$ and symptomatic or asymptomatic (ankle-brachial index $<0.9$ ) PAD. ${ }^{21,22}$

Subgroup analyses demonstrated consistency of benefit for the primary and key secondary end points, including for allcause death, including among those with $\mathrm{CAD},{ }^{18,23}$ with or without PAD, ${ }^{18,21}$ recent CABG (although no differences in graft patency were observed), ${ }^{24}$ diabetes, ${ }^{18}$ and CKD. ${ }^{18,25}$ Although the majority of patients with prior MI in COMPASS were $>2$ years removed from their most recent event, there was also consistency of benefit among those $(n=2423)$ whose MI occurred within the previous 2 years. ${ }^{23}$ Given the higher-risk nature of several of these subgroups, consistent relative reduction in events with rivaroxaban plus ASA compared with ASA alone translates into greater absolute risk reductions.

The findings from COMPASS are remarkably consistent with those observed in the Anti-Xa Therapy to Lower Cardiovascular Events in Addition to Standard Therapy in Subjects With Acute Coronary Syndrome 2-Thrombolysis in Myocardial Infarction 51 (ATLAS ACS-2-TIMI 51) trial. ${ }^{26}$ ATLAS ACS 2-TIMI 51 tested rivaroxaban $(2.5 \mathrm{mg}$ twice daily or $5 \mathrm{mg}$ twice daily) in addition to ASA or DAPT in patients with recent ACS and demonstrated that rivaroxaban resulted in a lower rate of $\mathrm{CV}$ death, MI, or stroke than placebo, and the dose of $2.5 \mathrm{mg}$ twice daily significantly lowered CV death and all-cause mortality. Rivaroxaban, even the $2.5 \mathrm{mg}$ twice daily arm, resulted in a significant increase in major bleeding $(2.1 \%$ vs $0.6 \%, P<0.001)$ and intracranial haemorrhage $(0.6 \%$ vs $0.2 \%, P=0.009)$, without a significant increase in fatal bleeding. The mean duration of rivaroxaban treatment in ATLAS ACS 2-TIMI 51 trial was approximately 13 months; in contrast, patients with prior MI in COMPASS were enrolled a mean of approximately 7 years after the acute event and continued to receive treatment for a mean of 23 months. 
Table 1. Antiplatelet therapy

\begin{tabular}{lc}
\hline \hline Strategy & Patients \\
\hline $\begin{array}{l}\text { DAPT after ACS } \\
\text { CURE }^{2}\end{array}$ & $\begin{array}{c}\text { Acute non-ST-elevation ACS } \\
\mathrm{N}=12,562\end{array}$ \\
& \\
& \\
PLATO $^{3}$ & $\begin{array}{c}\text { Acute ACS with or without ST- } \\
\text { elevation ACS } \\
\end{array}$ \\
$\mathrm{N}=18,624$
\end{tabular}

TRITON-TIMI $38^{4}$

Acute ACS scheduled for PCI $\mathrm{N}=13,608$

Post PCI (58\% post-ACS) $\mathrm{N}=2993$

Post-PCI (30\% post-ACS) with 1 high ischemic or bleeding risk $\mathrm{N}=7119$

Shorter duration of DAPT

Multiple open-label noninferiority trials $s^{5,6}$

Mono APT vs DAPT

GLOBAL LEADERS $^{8}$

SMART-CHOICE ${ }^{9}$

TWILIGHT $^{10}$

\author{
Extension of DAPT treatment \\ period with $\mathrm{P}_{2} \mathrm{Y}_{12} \mathrm{i}$ \\ PEGASUS TIMI $54^{12}$
}

Prior MI 1-3 y earlier, $\mathrm{N}=21,162$
Ticagrelor $180 \mathrm{mg}$ then $90 \mathrm{mg}$ daily vs clopidogrel $300 \mathrm{mg}$ then $75 \mathrm{mg}$ daily for $12 \mathrm{mo}$

All patients taking ASA

Prasugrel $60 \mathrm{mg}$ then $10 \mathrm{mg}$ daily vs clopidogrel $300 \mathrm{mg}$ then 75 mg daily

All patients taking ASA

Duration of DAPT 1, 6 mo vs $1 \mathrm{y}$

ASA + ticagrelor for 1 mo then ticagrelor for 23 mo vs ASA + clopidogrel for 12 mo then ASA for $12 \mathrm{mo}$

3 mo DAPT followed by DAPT vs monotherapy with $\mathrm{P}_{2} \mathrm{Y}_{12}$

3 mo DAPT without bleeding or ischemic event, then ticagrelor + ASA vs ticagrelor
Outcome

Clopidogrel + ASA reduced CVD/ $\mathrm{MI} /$ stroke $20 \%$

Major bleeding increased 38\% but no increase in life-threatening or fatal bleeding

$\mathrm{CVD} / \mathrm{MI} /$ stroke reduced $16 \%$; HR, 0.84 (0.77-0.92)

MI, CV 5/8/20 and all-cause death significantly reduced

Increased non-CABG-related bleeding

CVD/MI/stroke reduced 19\%; HR, 081 (0.73-0.90)

Reduced MI, stent thrombosis, urgent revascularization

Major bleeding increased 32\%, increased life-threatening and fatal bleeding

Nonstatistical increase in ischemic events

At 2 y ticagrelor: NS lower death/ MI; HR, 0.87 (0.75-1.01)

Bleeding rates in patients with ACS lower with 1 mo DAPT/23 mo ticagrelor

Similar all-cause death/MI/stroke. Only 5 stent thromboses.

Bleeding lower in monotherapy $2.0 \%$ vs $3.4 \%)$

Bleeding (BARC type 2, 3, or 5)

$4.0 \%$ vs $7.1 \%$; HR, $0.56(0.45-$ $0.68)$

No difference in all-cause mortality/MI/stroke

Similar outcomes in patients with an without ACS

2 doses of ticagrelor reduced CVD/ $\mathrm{MI} /$ stroke by similar amounts compared with placebo $(90 \mathrm{mg}$ $15 \%, 60 \mathrm{mg} \mathrm{16 \% )}$

TIMI major bleeding increased (90

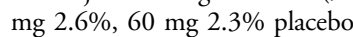
$1.06 \%)$

Similar ICH/fatal bleeding

ACS, acute coronary syndrome; APT, antiplatelet therapy; ASA, acetylsalicylic acid; BARC, Bleeding Academic Research Consortium; BID, twice per day; CABG, coronary artery bypass grafting; CV, cardiovascular; CVD, cardiovascular disease; CURE, Clopidogrel in Unstable Angina to Prevent Recurrent Ischemic Events; DAPT, dual antiplatelet therapy; GLOBAL LEADERS, Ticagrelor Plus Aspirin Followed by Ticagarelor Monotherapy vs a Current-Day Intensive Dual Antiplatelet Therapy in Patients Undergoing Percutaneous Coronary Intervention With Bivalirudin and Biomatrix Family Drug-Eluting Stents; HR, hazard ratio; ICH, intracranial haemorrhage; MI, myocardial infarction; PEGASUS TIMI 54, Prevention of Cardiovascular Events in Patients With Prior Heart Attack Using Ticagrelor Tablets Compared to Placebo on a Background of Aspirin-Thrombolysis in Myocardial Infarction 54; PCI, percutaneous coronary intervention; PLATO, Platelet Inhibition and Patient Outcomes; SMART CHOICE, Smart Angioplasty Research Team: Comparison Between P2Y12 Antagonist Monotherapy vs Dual Antiplatelet Therapy in Patients Undergoing Implantation of Coronary Drug-Eluting Stents; TIMI, thrombolysis in myocardial infarction; TRITONTIMI 38, TRial to assess Improvement in Therapeutic Outcomes by optimizing platelet inhibition with prasugrel-Thrombolysis in Myocardial Infarction 38; TWILIGHT, Ticagrelor With Aspirin or Alone in High-Risk Patients After Coronary Intervention.

Despite the clear benefits in reducing ischemic events with extended DAPT or rivaroxaban plus ASA in patients post-MI, dual inhibition with antiplatelet or anticoagulation is also associated with increased bleeding risk. Thus, the identification of the key risk factors associated with higher ischemic and bleeding risk may help the clinician and patient in the decision-making process. Several risk scores, assessing mainly bleeding but sometimes incorporating elements of ischemic risk, have been developed. ${ }^{27-30}$ However, these are generally focused on post-PCI (and not exclusively patients post-ACS), have been developed mainly within clinical trial populations, and have not been generally well validated in routine clinical practice. $^{31}$ A recent observational analysis from Sweden included $>100,000$ invasively managed patients with MI 
Table 2. Oral anticoagulation after ACS

\begin{tabular}{|c|c|c|c|}
\hline & Patients & Treatment & Outcomes \\
\hline COMPASS $^{18}$ & $\begin{array}{l}\text { Chronic ASCVD (CAD }(91 \%) \text { or } \\
\text { PVD (both cerebrovascular and } \\
\text { lower limb vascular disease) } \\
\text { For patients aged }<65 \mathrm{y} \text {, also ASCVD } \\
\text { in } 2 \text { territories or } 2 \text { additional risk } \\
\text { factors (current smoker, diabetes, } \\
\text { CKD, or nonlacunar stroke) } \\
62 \% \text { with prior MI (mean time } 7 \text { y) } \\
\text { Excluded patients needing DAPT or } \\
\text { OAC } \\
\text { Stroke }<1 \mathrm{mo}, \mathrm{HF}, \mathrm{LVEF}<30 \% \text {, } \\
\text { eGFR }<15 \mathrm{~mL} / \mathrm{min} / 1.73 \mathrm{~m}^{2} \\
\mathrm{~N}=27,395\end{array}$ & $\begin{array}{l}\text { Rivaroxaban } 2.5 \mathrm{mg} \text { BID + ASA vs } \\
\text { rivaroxaban } 5 \mathrm{mg} \text { BID } \\
\text { vs ASA }\end{array}$ & $\begin{array}{l}\text { Study stopped prematurely because of } \\
\text { early benefit of rivaroxaban } \\
\text { For rivaroxaban } 2.5 \text { mg BID +ASA } \\
\text { CVD/MI/stroke reduced } 24 \% \text { (HR, } \\
0.76 \text {; } 0.66-0.86 \text { ) } \\
\text { CVD reduced } 22 \% \text { (HR, } 0.78 ; 0.64- \\
0.96 \text { ) } \\
\text { All-cause mortality reduced } 18 \% \\
\text { MI not significantly reduced } \\
\text { No additional benefit from rivaroxaban } \\
5 \text { mg BID } \\
\text { Major limb adverse events (severe limb } \\
\text { ischemia leading to amputation or } \\
\text { revascularisation) reduced (HR, } \\
0.54 ; 0.34-0.82 \text { ) } \\
\text { Major bleeding increased 3.9\% vs } \\
1.9 \% \text { ( } 50 \% \text { was GI) HR, } 1.7 \text { (1.40- } \\
2.05 \text { ) } \\
\text { No increase in intracranial or fatal } \\
\text { bleeding }\end{array}$ \\
\hline ATLAS ACS-2 TIMI $51^{26}$ & Recent ACS & $\begin{array}{l}\text { On ASA or DAPT } \\
\text { Rivaroxaban } 2.5 \mathrm{mg} \text { BID or } 5 \mathrm{mg} \text { BID } \\
\text { vs placebo for } 13 \mathrm{mo}\end{array}$ & $\begin{array}{l}\text { Rivaroxaban reduced primary EP } \\
\text { (CVD/MI/stroke) } 16 \% \text {; HR, } 0.84 \\
(0.74-0.96) \text {. Similar primary EP } \\
\text { benefits with } 2.5 \mathrm{mg} \text { BID and } 5 \mathrm{mg} \\
\text { BID } \\
\text { Rivaroxaban } 2.5 \mathrm{mg} \text { BID reduced } \\
\text { CVD }(2.7 \% \text { vs } 4.5 \%) \text { but no } \\
\text { reduction of CVD with } 5 \mathrm{mg} \text { BID } \\
\text { Rivaroxaban } 2.5 \mathrm{mg} \text { BID: major } \\
\text { bleeding increased } 2.1 \% \text { vs } 0.2 \% \text {, } \\
\text { intracranial haemorrhage } 0.6 \% \text { vs } \\
0.2 \% \text {, but no increase in fatal } \\
\text { bleeding }\end{array}$ \\
\hline
\end{tabular}

ACS, acute coronary syndrome; APT, antiplatelet therapy; ASA, acetylsalicylic acid; ASCVD, atherosclerotic cardiovascular disease; ATLAS ACS-2 TIMI 51, the Anti-Xa Therapy to Lower Cardiovascular Events in Addition to Standard Therapy in Subjects With Acute Coronary Syndrome 2-Thrombolysis in Myocardial Infarction 51; BID, twice per day; CAD, cardiovascular artery disease; CKD, chronic kidney disease; COMPASS, Cardiovascular Outcomes for People Using Anticoagulation Strategies; CVD, cardiovascular disease; DAPT, dual antiplatelet therapy; eGFR, estimated glomerular filtration rate; EP, end point; GI, gastrointestinal; HF, heart failure; HR, hazard ratio; ICH, intracranial haemorrhage; LVEF, left ventricular ejection fraction; MI, myocardial infarction; OAC, oral anticoagulant; PAD, peripheral artery disease; PCI, percutaneous coronary intervention; TIMI, thrombolysis in myocardial infarction.

(2006-2014), of whom $21 \%$ experienced CV death, MI, or stroke and $6 \%$ major bleeding during a median of 3.6 years of follow-up. ${ }^{32}$ Six factors (age $\geq 65$ years, CKD, diabetes, multivessel disease, prior bleeding, and prior MI) were identified as being independently associated with ischemic events, and all but prior MI were also independently associated with major bleeding. The majority (54\%) had $\geq 2$ risk factors, and with each added risk factor, there was a marked but gradual increase in the incidence of ischemic events; this was also seen for major bleeding, but to a lesser extent and largely driven by prior bleeding as the strongest risk factor.

These findings suggest that for the majority of patients with prior MI who would have been eligible for the PEGASUS-TIMI 54 or COMPASS trial, particularly those without prior major bleeding, the high ischemic risk (including $\mathrm{CV}$ and all-cause mortality) warrants consideration of extended DAPT (eg, ticagrelor $60 \mathrm{mg}$ twice daily plus ASA) or dual pathway (rivaroxaban $2.5 \mathrm{mg}$ twice daily plus ASA) as effective secondary prevention therapy. Some provincial formularies provide coverage for the use of ticagrelor $90 \mathrm{mg}$ but not $60 \mathrm{mg}$ twice daily; thus, the $60 \mathrm{mg}$ twice daily dosing in the PEGASUS-TIMI 54 trial demonstrated similar cardiovascular efficacy benefit but with a trend toward less excess bleeding than the $90 \mathrm{mg}$ twice daily. ${ }^{15,33}$ Clopidogrel could be considered an alternative, particularly when access to ticagrelor or rivaroxaban is not possible, given the benefits observed in a subgroup (previous MI) analysis of the Clopidogrel for High Atherothrombotic Risk and Ischemic Stabilisation Management and Avoidance (CHARISMA) trial, although the overall trial primary outcome was neutral when compared with ASA alone.

\section{Lipid Modification Therapy}

Clinical trials discussed in this section are summarised in Table 3. High-intensity statin therapy (ie, atorvastatin 40-80 $\mathrm{mg} /$ day or rosuvastatin $20-40 \mathrm{mg} /$ day) remains the cornerstone of lipid-lowering treatment in patients post-ACS. ${ }^{34,35}$ On the basis of the Improved Reduction of Outcomes: Vytorin Efficacy International Trial (IMPROVE-IT) trial, ${ }^{36}$ for those with a recent ACS, the 2016 Canadian Dyslipidemia Guidelines suggested consideration be given to more aggressive targets, including a low-density lipoprotein cholesterol (LDL-C) $<1.8 \mathrm{mmol} / \mathrm{L}$, noting that "this might require the combination of ezetimibe (or other nonstatin medications) with maximally tolerated statin." 34 
Table 3. Lipid modification therapy

Patients

\section{High-intensity statins}

PROVE IT $22^{35}$

4162 patients with ACS in

previous $10 \mathrm{~d}$

ravastatin $40 \mathrm{mg}$ vs atorvastatin

$80 \mathrm{mg}$

Addition of ezetimibe

IMPROVE IT $^{36}$

18,144 patients with ACS in previou

$10 \mathrm{~d}$, and LDL-C 1.3-2.6 mmol/L

\section{Addition of PCSK9}

FOURIER $^{37}$

Established ASCVD

$81 \%$ with prior $\mathrm{M}$

LDL C $>1.8 \mathrm{mmol} / \mathrm{L}$

ODYSSEY OUTCOMES

18,924 patients with prior ACS 1-12 $\mathrm{mo}$, and $\mathrm{LDL} \geq 1.8$

REDUCE-IT ${ }^{51}$

8179 patients with established CVD (71\%) or $\geq 50 y$ with DM and CV risk factor $(29 \%)$ with fasting triglycerides $1.52-5.63 \mathrm{mmol} / \mathrm{L}$ and LDL-C $1.06-2.59 \mathrm{mmol} / \mathrm{L}$ on a
Maximally tolerated statin + evolucomab vs placebo

Maximally tolerated statin + alirocumab vs placebo adjusted to achieve LDL-C $0.65-1.29 \mathrm{mmol} / \mathrm{L}$

Icosapent ethyl $2 \mathrm{~g}$ twice daily vs placebo added to maximally tolerated statin therapy
Ezetimibe + simvastatin vs simvastatin
LDL-C Pravastatin $2.46 \mathrm{mmol} / \mathrm{L}$ Atorvastatin $1.60 \mathrm{mmol} / \mathrm{L}$

MI, stroke, unstable angina,

coronary revascularization) reduced

$16 \%$ (HR, 0.84-0.95

LDL-C Simvastatin $1.8 \mathrm{mmol} / \mathrm{L}$ Simvastatin + ezetimibe $1.4 \mathrm{mmo} /$ L. At 6 y primary EP (CVD, MI, stroke, unstable angina, coronary revascularization) reduced ( $\mathrm{HR}$, 0.94; 0.89-0.99). Absolute risk reduction $2 \%$

LDL-C reduced $59 \%$ to $0.78 \mathrm{mmol} / \mathrm{L}$ At 2.2 y primary EP (CVD, MI, stroke, unstable angina, coronary revascularization) reduced (HR, $0.85(0.79-0.92)$ (0.73-0.88)

Lower event rates relate to achieved LDL-C even to $<0.2 \mathrm{mmol} / \mathrm{L}$

LDL-C reduced $63 \%$ to $0.98 \mathrm{mmol} / \mathrm{L}$

At 2.8 y primary EP (CVD, MI, stroke, unstable angina, coronary HR, 0.85 (0.78-0.93)

Nonfatal MI and stroke significantly reduced

Primary EP (CVD, MI, stroke, revascularization, unstable angina) HR, $0.75(0.68-0.83)$

Secondary EP (CVD, MI, stroke) HR, $0.74(0.65-0.83)$

CV death HR, 0.80 (0.66-0.98)
At 24 mo primary EP (all-cause death,

$\mathrm{CVD} / \mathrm{MI} /$ stroke reduced (HR, 0.80
Increased benefit in patients with diabetes

Increased minor injection site reaction

- $\geq 2$ prior mo

- $\mathrm{MI}<2$ y

- Extensive CAD

Increased minor injection site reaction

Small increase in hospitalization for atrial fibrillation $(3.1 \%$ vs $2.1 \% P=$ $0.004)$ and serious bleeding (2.7 vs $2.1 \% P=0.06$ ) Greater benefit with

ACS, acute coronary syndrome; ASCVD, atherosclerotic cardiovascular disease; CAD, coronary artery disease; CV, cardiovascular; CVD, cardiovascular disease; EP, end point; HR, hazard ratio; IMPROVE-IT, Improved Reduction of Outcomes: Vytorin Efficacy International Trial; LDL-C, low-density lipoprotein cholesterol; MI, myocardial infarction; ODYSSEY OUTCOMES, Evaluation of Cardiovascular Outcomes

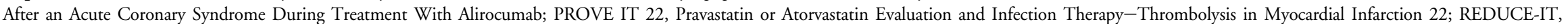
Reduction of Cardiovascular Events with Icosapent Ethyl-Intervention Trial. 
Table 4. Glucose-lowering agents with CV benefits

\begin{tabular}{|c|c|c|c|}
\hline & Patients & Treatment & Outcomes \\
\hline \multicolumn{4}{|l|}{ SGLT2 inhibitors } \\
\hline \multirow[t]{4}{*}{ EMPA-REG Outcome $e^{56}$} & T2DM $\mathrm{A}_{1} \mathrm{C} 7.0 \%-10.0 \%$ & Empagliflozin $10 \mathrm{mg}$ vs $5 \mathrm{mg}$ vs & CVD/MI/stroke; HR, 0.86 (0.74- \\
\hline & Established CVD eGFR > $30 \mathrm{~mL} /$ & & \\
\hline & $\min / 1.73 \mathrm{~m}^{2} \mathrm{~N}=7020$ & Observation time $3.2 \mathrm{y}$ & CVD reduced $38 \%$ \\
\hline & & & All-cause mortality reduced $32 \%$ \\
\hline \multirow[t]{4}{*}{ CANVAS $^{57}$} & T2DM $A_{1}$ C $7.0 \%-10.5 \%$ & Canagliflozin & MACE reduced $14 \%$; HR, $0.86(0.75$ \\
\hline & Established CVD (72\%) or multiple & & $0.97)$ \\
\hline & $\begin{array}{l}\text { ASCVD risk factors eGFR }>30 \\
\mathrm{~mL} / \mathrm{min} / 1.73 \mathrm{~m}^{2}\end{array}$ & & $\begin{array}{l}\text { HFH reduced } 33 \% \text {; HR, } 0.67 \text { (0.52- } \\
0.87)\end{array}$ \\
\hline & Follow-up 3.6 y N = 10142 & & $\begin{array}{l}\text { 2-fold increase in peripheral lower limb } \\
\text { amputations }\end{array}$ \\
\hline \multirow[t]{6}{*}{ DECLARE-TIMI $58^{58}$} & T2DM A $A_{1}$ C $6.5 \%-12 \%$ & Dapagliflozin $10 \mathrm{mg}$ vs placebo & $\mathrm{CVD} / \mathrm{HFH}$ reduced $17 \%$ (HR, $0.73-$ \\
\hline & Established CVD or multiple ASCVD & & $\begin{array}{l}0.95) \\
M A C F\end{array}$ \\
\hline & $\begin{array}{l}\text { risk factors }(10,100) \text { eGFK }>30 \\
\mathrm{~mL} / \mathrm{min} / 1.73 \mathrm{~m}^{2}\end{array}$ & & $\begin{array}{l}\text { MACE not reduced } \\
\text { CVD not reduced }\end{array}$ \\
\hline & Follow-up 4.2 y $\mathrm{N}=17160$ & & HFH reduced; HR, 0.73 (0.61-0.88) \\
\hline & & & Genital infection increased \\
\hline & & & $\begin{array}{l}\text { Diabetic ketoacidosis increased } 0.3 \% \\
\text { vs } 0.1 \%\end{array}$ \\
\hline \multirow[t]{5}{*}{ CREDENCE $^{59}$} & T2DM A1C & Canagliflozin $100 \mathrm{mg}$ vs placebo & ESKD/doubling creatinine/renal or \\
\hline & $\begin{array}{l}\text { Albuminuria CKD eGFR 30-90 + } \\
\text { albuminuria ACR 3000-5000 mg/g }\end{array}$ & & $\begin{array}{l}\text { cardiac death reduced } 30 \% \text {; HR, } \\
0.70(0.70-0.82)\end{array}$ \\
\hline & Follow-up 2.62 y N $=4401$ & & CVD reduced $20 \%$ \\
\hline & & & $\mathrm{HFH}$ reduced $29 \%$ \\
\hline & & & No increase amputations of fractures \\
\hline \multicolumn{4}{|l|}{$G L P-1 R A$} \\
\hline \multirow[t]{3}{*}{ LEADER $^{62}$} & $\begin{array}{l}\text { T2DM + established CVD or risk } \\
\text { factors }\end{array}$ & Liraglutide s/c daily vs placebo & $\begin{array}{l}\text { CVD/MI/stroke reduced } 13 \% \text {; HR, } \\
0.87(0.78-0.97)\end{array}$ \\
\hline & $\begin{array}{l}\text { Follow-up } 3.8 \text { y } \\
\mathrm{N}=9340\end{array}$ & & $\begin{array}{l}\text { CVD reduced } 22 \% \text {, no reduction } \\
\text { HFH }\end{array}$ \\
\hline & & & Increase GI adverse effects \\
\hline \multirow[t]{2}{*}{ SUSTAIN $6^{63}$} & $\begin{array}{l}\text { T2DM + established CVD ( } 83 \% \text { with } \\
\text { CVD or CKD) or risk factors }\end{array}$ & Semaglutide $0.5-1.0 \mathrm{mg} \mathrm{s} / \mathrm{c}$ weekly & $\begin{array}{l}\text { CVD/MI/stroke reduced } 26 \% \text {; HR, } \\
0.74(0.58-0.95\end{array}$ \\
\hline & & & Nonfatal stroke reduced 39\% \\
\hline \multirow[t]{2}{*}{ REWIND $^{64}$} & $\begin{array}{l}\text { T2DM + established CVD ( } 83 \% \text { with } \\
\text { CVD or CKD) or risk factors }\end{array}$ & $\begin{array}{l}\text { Dulaglutide } 1.5 \mathrm{mg} \text { s/c weekly vs } \\
\text { placebo }\end{array}$ & $\begin{array}{l}\text { CVD/MI/stroke reduced } 12 \% ; \mathrm{HR} \text {, } \\
0.88(0.79-0.99)\end{array}$ \\
\hline & FU 5.4 y & & Increased GI adverse effects \\
\hline \multirow[t]{2}{*}{ Harmony outcomes ${ }^{65}$} & T2DM and CVD & Albiglutide $30-50 \mathrm{mg} s / \mathrm{c}$ weekly, FU & $\mathrm{CVD} / \mathrm{MI} /$ stroke reduced $22 \%$; HR, \\
\hline & $\mathrm{N}=9463$ & $1.6 \mathrm{y}$ & $0.78(0.68-0.90)$ \\
\hline
\end{tabular}

ACR, albumin to creatinine ratio; ASCVD, atherosclerotic cardiovascular disease; CANVAS, Canagliflozin Cardiovascular Assessment Study; CKD, chronic kidney disease; CV, cardiovascular; CVD, cardiovascular disease; CREDENCE, Canagliflozin and Renal Events in Diabetes With Established Nephropathy Clinical Evaluation; DECLARE-TIMI 58, Dapagliflozin Effect on Cardiovascular Events-Thrombolysis in Myocardial Infarction 58; eGFR, estimated glomerular filtration rate; EMPA-REG Outcome, Empagliflozin Cardiovascular Outcome Event Trial in Type 2 Diabetes Mellitus Patients; ESKD, end-stage kidney disease; FU, followup; GI, gastrointestinal; GLP-1 RA, glucagon-like peptide-1 receptor agonist; HARMONY, albiglutide and cardiovascular outcomes in patients with type 2 diabetes and cardiovascular disease; HFH, heart failure hospitalisation; HR, hazard ratio; LEADER, Liraglutide Effect and Action in Diabetes: Evaluation of Cardiovascular Outcome Results; MACE, major adverse cardiovascular events; MI, myocardial infarction; REWIND, Researching Cardiovascular Events With a Weekly Incretin in Diabetes; s/c, subcutaneously; SGLT2, sodium-glucose co-transporter 2; T2DM, type 2 diabetes mellitus.; SUSTAIN 6, Trial to Evaluate Cardiovascular and Other Long-term Outcomes with Semaglutide in Subjects with Type 2 Diabetes 6.

Recent data on the PCSK9 inhibitors evolocumab and alirocumab $^{37,38}$ have shown the additive cardiovascular benefit of further LDL reduction in patients with a recent ACS mainly receiving high-intensity statin therapy.

The Further Cardiovascular Outcomes Research With PCSK9 Inhibition in Subjects With Elevated Risk (FOURIER) trial $^{37}$ was a double-blind, placebo-controlled study with the PCSK9 inhibitor evolocumab in patients aged 40 to 85 years with established atherosclerotic CVD (including $81 \%$ with a prior myocardial infarction [MI]) and LDL-C $\geq 1.8 \mathrm{mmol} / \mathrm{L}$ or non-HDL-C $\geq 2.6 \mathrm{mmol} / \mathrm{L}$ despite maximally tolerated statin therapy. Relevant exclusion criteria were recent MI or stroke within 4 weeks, planned or expected cardiac surgery or revascularization within 3 months after randomization, New York Heart Association class III-IV HF, or left ventricular ejection fraction $<0.30$. After 48 weeks, LDL-C was reduced $59 \%$ to $0.78 \mathrm{mmol} / \mathrm{L}$ with evolocumab $(140 \mathrm{mg}$ every 2 weeks or $420 \mathrm{mg}$ monthly subcutaneously). After a median follow-up of 2.2 (interquartile range, 1.8-2.5) years, the primary end point (time to first CV death, MI, stroke, hospitalization for unstable angina, or coronary revascularization) was reduced by $15 \%$ (HR, $0.85 ; 95 \%$ confidence interval [CI], 0.79-0.92) and the secondary end point (CV death, MI, or stroke) by 20\% (HR, 0.80; 95\% CI, 0.730.88 ). Several additional secondary end points (eg, MI, stroke, coronary revascularization) were also significantly lower, yet no differences were observed between evolocumab and placebo for $\mathrm{CV}$ or all-cause mortality. There was no significant difference between the evolocumab and placebo groups with regard to adverse events (including new-onset diabetes and neurocognitive events), with the exception of injection-site reactions, which were 
more common with evolocumab $(2.1 \%$ vs $1.6 \%)$. In a prespecified secondary analysis of 25,982 patients (94\%) in FOURIER who had an LDL-C measured at 4 weeks (and who had not experienced a primary end point event), there was a highly significant linear relationship between lower LDL-C concentrations and lower risk of the primary and secondary efficacy composite end points; this extended to the bottom first percentile (LDL-C $<0.2 \mathrm{mmol} / \mathrm{L}) .{ }^{39}$ Conversely, no significant association was observed between achieved LDL-C and safety outcomes, either for all serious adverse events or any of the other 9 prespecified safety events.

As part of another prespecified analysis, a total of 22,351 patients $(81 \%$ of overall trial) had a prior MI and were stratified on the basis of the (1) number of prior MIs $(24 \%$ had $\geq 2$ prior MIs); (2) timing of prior MIs (38\% had their qualifying $\mathrm{MI}$ within 2 years of randomization; median time from that MI was $0.6(0.3-1.2)$ years); and (3) extent of CAD (25\% had residual multivessel CAD defined as $\geq 40 \%$ stenosis in $\geq 2$ large vessels). ${ }^{40}$ The relative risk reductions (18\%-21\%) with evolocumab for the primary end point tended to be greater in the high-risk subgroups. Given the higher baseline risk, the respective absolute risk reductions at 3 years exceeded $3 \%$ in the high-risk groups $(3.4 \%, 3.7 \%$, and $3.6 \%)$ vs approximately $1 \%$ in the low-risk groups $(0.8 \%$, $1.3 \%$, and $1.2 \%)$.

The Evaluation of Cardiovascular Outcomes After an Acute Coronary Syndrome During Treatment With Alirocumab (ODYSSEY OUTCOMES) $\operatorname{trial}^{38}$ was a doubleblind, placebo-controlled study with the PCSK9 inhibitor alirocumab in 18,924 patients $\geq 40$ years of age with an ACS (MI or high-risk unstable angina) 1-12 (median time 2.6 [1.74.3]) months before randomization and an LDL-C $\geq 1.8$ $\mathrm{mmol} / \mathrm{L}$, non-HDL-C $\geq 2.6 \mathrm{mmol} / \mathrm{L}$, or apolipoprotein $\mathrm{B}$ $\geq 0.8 \mathrm{~g} / \mathrm{L}$ and receiving high-intensity ( $\sim 89 \%$ of patients) or maximally tolerated statin therapy. Relevant exclusion criteria were New York Heart Association class III-IV HF or LVEF < 0.25 , coronary revascularization within 2 weeks before, or planned after, randomization, or prior haemorrhagic stroke. The dose of alirocumab (75-150 mg every 2 weeks subcutaneously) was blindly adjusted to achieve an on-treatment LDL-C between 0.65 and $1.29 \mathrm{mmol} / \mathrm{L}$ while avoiding sustained LDL-C $<0.4 \mathrm{mmol} / \mathrm{L}$. Alicuromab reduced LDL-C after 4 months by $63 \%$ to $0.98 \mathrm{mmol} / \mathrm{L}$ and at 48 months by $55 \%$ to $1.4 \mathrm{mmol} / \mathrm{L}$. After a median follow-up of 2.8 (2.33.4) years, the primary end point (time to first coronary heart disease death, nonfatal MI, fatal or nonfatal ischemic stroke, or unstable angina requiring hospitalization) was reduced by $15 \%$ (HR, 0.85 [0.78-0.93]). Nonfatal MI, stroke, and unstable angina hospitalization were significantly reduced. Although both coronary heart disease and CV death were not significantly reduced, all-cause mortality was $15 \%$ lower (HR, $0.85[0.73-0.98])$ with alirocumab vs placebo. The incidence of adverse events was similar in the 2 groups, with the exception of local injection-site reactions $(3.8 \%$ in the alirocumab group vs $2.1 \%$ in the placebo group).

In summary, both studies show the cardiovascular benefit of lowering LDL-C below currently recommended levels with a PCSK9 inhibitor. Similar relative benefits were observed in a wide range of subgroups regardless of level of baseline LDLC, ${ }^{37,38}$ and including patients with diabetes, ${ }^{41,42}$ peripheral arterial $^{43}$ or polyvascular disease, ${ }^{44}$ type of ACS (ST-elevation,
non-ST-elevation MI or unstable angina), ${ }^{38}$ type of index ACS management (eg, coronary revascularization) or medical management and time from index ACS to ${ }^{37,38}$ randomisation. Thus, as per the European Society of Cardiology/European Atherosclerosis Society guidelines, ${ }^{45}$ very high-risk patientsincluding post-ACS - who do not achieve an LDL-C of $\leq 1.4$ $\mathrm{mmol} / \mathrm{L}$ after 4 to 6 weeks despite maximally tolerated statin and ezetimibe, adding a PCSK9 inhibitor is recommended. The greatest absolute risk reductions (with reasonable numbers needed to treat and associated cost-effectiveness) will be realized in those with a recent ACS, residual multivessel $\mathrm{CAD}$ (including those with prior $\mathrm{CABG},{ }^{46}$ polyvascular disease (eg, CAD and PAD or cerebrovascular disease), diabetes, and those whose LDL-C remains far from target (eg, $\geq 2.6$ $\mathrm{mmol} / \mathrm{L})$. Finally, the PCSK9 inhibitors are remarkably safe and well tolerated (ie, indistinguishable adverse event profile compared with placebo apart from a small absolute increase in the frequency of local injection site reactions [erythema, pruritus, bruising]). Further, the lowest levels of LDL-C achieved are associated with the lowest $\mathrm{CV}$ event rates and no apparent safety signal, at least over the 2- to 5-year duration of treatment experience in the FOURIER and ODYSSEY OUTCOMES trials.

Elevated triglycerides are an independent marker for an increased risk of ischemic events. ${ }^{47}$ In previous randomized trials, extended-release niacin, fibrates, and n-3 fatty acid supplementation, despite lowering triglyceride levels, have not reduced CV event rates when added to statin therapy. ${ }^{48,49}$ In contrast, in the Japan EPA Lipid Intervention Study (JELIS), 18,645 patients with hypercholesterolemia were randomly assigned to receive low-intensity statin therapy plus $1.8 \mathrm{~g}$ of EPA daily or statin therapy alone, and the risk of major coronary events was significantly lower in the EPA plus statin therapy compared with the statin alone group. ${ }^{50}$ However, JELIS was an open-label design study without a placebo group, used a low-intensity statin, and was conducted in a single country. The Reduction of Cardiovascular Events with Icosapent Ethyl-Intervention Trial (REDUCE-IT) was an international, multicenter, randomized, double-blind, placebo-controlled study of patients aged $\geq 45$ years with established cardiovascular disease or age $\geq 50$ years with diabetes mellitus and 1 additional risk factor, who had been receiving statin therapy and who had a fasting triglyceride level of 1.52 to $5.63 \mathrm{mmol} / \mathrm{L}$ and a LDL-C level of 1.06 to 2.59 $\mathrm{mmol} / \mathrm{L}$. Patients enrolled in the trial included those with prior MI (47\%), symptomatic PAD (9\%), prior ischemic stroke $(6 \%)$, or transient ischemic attack (5\%). ${ }^{51}$ Additional baseline risk factors included hypertension (87\%), diabetes mellitus (59\%), eGFR $<60 \mathrm{~mL} / \mathrm{min} / 1.73 \mathrm{~m}^{2}(22 \%)$, heart failure (18\%), and current daily cigarette smoking (15\%). Most patients at baseline were taking evidence-based CV medications, including antiplatelet agents (79\%), betablockers $(71 \%)$, and an angiotensin-converting enzyme inhibitor or angiotensin receptor blockers (ARBs) (78\%). The median LDL-C was $1.94 \mathrm{mmol} / \mathrm{L}$, and fasting serum triglycerides were $2.44 \mathrm{mmol} / \mathrm{L}$ (all patients were receiving statin therapy, including high-intensity in $31 \%$ and $6 \%$ were on ezetimibe at baseline). The patients were randomly assigned to receive $2 \mathrm{~g}$ of icosapent ethyl twice daily (total daily dose, $4 \mathrm{~g}$ ) or placebo. At a median follow-up of 4.9 years, the primary end point composite of $\mathrm{CV}$ death, nonfatal $\mathrm{MI}$, nonfatal 
stroke, coronary revascularization, or unstable angina, occurred in $17.2 \%$ of the patients in the icosapent ethyl group compared with $22.0 \%$ of the patients in the placebo group (HR, 0.75 [0.68 to 0.83]; $P<0.001$ ). This large absolute difference $(4.8 \%)$ leads to an overall number-needed-to-treat (over $\sim 5$ years) of 21 . The corresponding key secondary end point (composite of $\mathrm{CV}$ death, nonfatal MI, or nonfatal stroke) rates were $11.2 \%$ vs $14.8 \%$ (HR, 0.74 [0.65-0.83]; $P$ $<0.001)$. Further, the rates of additional ischemic end points, as assessed according to a prespecified hierarchical schema, were significantly lower in the icosapent ethyl group than in the placebo group, including CV death (4.3\% vs $5.2 \%$; HR, 0.80 [0.66-0.98]; $P=0.03$ ) and fatal or nonfatal stroke (HR, $0.72[0.55-0.93])$. The rate of death from any cause was $6.7 \%$ in the icosapent ethyl group vs $7.6 \%$ in the placebo group (HR, 0.87 [0.74-1.02]).

The significantly lower risk of major adverse cardiovascular events with icosapent ethyl occurred irrespective of the attained triglyceride level at 1 year $(\geq 1.69$ or $<1.69 \mathrm{mmol} /$ $\mathrm{L}$ ), suggesting that the CV risk reduction was not associated with attainment of a more normal triglyceride level.

The overall rates of adverse and serious adverse events leading to study drug discontinuation were similar in the 2 groups. The rate of atrial fibrillation was significantly higher in the icosapent ethyl group (5.3\% vs 3.9\%), including the prespecified and adjudicated tertiary end point of hospitalization for atrial fibrillation or $(3.1 \%$ vs $2.1 \%, P=0.004)$. The rates of peripheral edema (6.5\% vs $5.0 \%)$ and serious adverse bleeding $(2.7 \%$ vs $2.1 \%$; although not for serious intracranial or gastrointestinal bleeding, haemorrhagic stroke end points, or bleeding-associated deaths) were higher with icosapent ethyl; in contrast, the rate of anemia was significantly lower in the icosapent ethyl group ( $4.7 \%$ vs $5.8 \%$ ), as were the rates of diarrhea $(9.0 \%$ vs $11.1 \%)$ and gastrointestinal adverse events $(33.0 \%$ vs $35.1 \%$ ). In prespecified analyses examining not only first events but also recurrent and total ischemic events, an approximate $30 \%$ reduction was observed, which will favourably affect evaluations of cost-effectiveness. ${ }^{52,53}$ Health Canada has approved icosapent ethyl based upon REDUCE-IT. A recent analysis of the Ontario population suggests that approximately $25 \%$ of patients with ASCVD have hypertriglyceridaemia and "controlled" LDL-C; these patients were demographically similar to those in REDUCE-IT with comparable event rates. ${ }^{47}$ Thus, in patients post-ACS with elevated triglyceride levels despite LDL-C lowering therapy (eg, $\geq 2 \mathrm{mmol} / \mathrm{L}$, recognizing that $10 \%$ of the REDUCE-IT population with a baseline triglyceride $<1.69 \mathrm{mmol} / \mathrm{L}$ derived similar relative benefit), consideration of icosapent ethyl $2 \mathrm{~g}$ twice daily to reduce important CV events is warranted.

\section{Glucose-Lowering Agents With Cardiovascular Benefit}

Recent clinical trials have shown that both sodium-glucose co-transporter 2 (SGLT2) Inhibitors and glucagon-like peptide-1 receptor agonist (GLP-1 RA) can reduce CV events in patients with type 2 diabetes mellitus and atherosclerotic CV disease $^{54,55}$ (Table 4). Four cardiovascular outcome trials with SGLT2 inhibitors have been reported, with empagliflozin (Empagliflozin Cardiovascular Outcome Event Trial in Type 2 Diabetes Mellitus Patients [EMPA-REG Outcome] ${ }^{56}$ ), canagliflozin (Canagliflozin Cardiovascular Assessment Study [CANVAS $^{57}$ ), and dapagliflozin (Dapagliflozin Effect on Cardiovascular Events-Thrombolysis in Myocardial Infarction 58 [DECLARE-TIMI 58 $]^{58}$ ) and 1 primary renal outcome (Canagliflozin and Renal Events in Diabetes With Established Nephropathy Clinical Evaluation [CREDENCE $]^{59}$ ) trial. The inclusion criteria for established CVD and renal function differed between these studies: EMPA-REG Outcome included only patients with established CVD, whereas the proportion with CVD was $40 \%$ in DECLARE-TIMI $58,70 \%$ in CANVAS, and $50 \%$ in CREDENCE. The entry renal function criteria varied from eGFR $>60 \mathrm{~mL} / \mathrm{min} / \mathrm{m}^{2}$ in DECLARETIMI 58 to eGFR 30 to $90 \mathrm{~mL} / \mathrm{min} / \mathrm{m}^{2}$ plus urine microalbumin creatinine ratio $>300$ to $\leq 5000 \mathrm{mg} / \mathrm{g}$ in CREDENCE. Consequently, the mortality in the populations varied widely from 7.1 CV deaths/1000/year in DECLARETIMI 58 to 35/1000/year in CREDENCE.

The major adverse cardiovascular events (MACE) end point was reduced in EMPA-REG Outcome, CANVAS, and CREDENCE, but not reduced in DECLARE-TIMI 58, where the other dual primary end point of CV death/hospitalisation for heart failure was reduced by a significant $17 \%$. Cardiovascular mortality was reduced $38 \%$ in EMPA-REG Outcome and $22 \%$ in the CREDENCE trial. Hospitalisation for heart failure was reduced $27 \%$ to $35 \%$. All 4 trials showed a significant reduction of the composite renal end point, which included progression to macro-albuminuria, doubling or $40 \%$ increase of serum creatinine, need for chronic renal replacement therapy, or renal death.

Patients with a baseline history of cardiovascular disease receiving a SGLT2 inhibitor, had a significant reduction of major cardiovascular events, heart failure hospitalisation, and stabilisation of chronic kidney disease. However, in the CANVAS and DECLARE-TIMI 58 studies, patients with multiple risk factors yet no documented CVD, had no reduction of major $\mathrm{CV}$ events, yet maintained the heart failure and renal benefits. ${ }^{54}$ However, in the higher-risk patients in the CREDENCE study, ${ }^{59}$ patients with and without a history of CVD had benefit In the EMPA-REG Outcome trial, patients with a history of MI or stroke had the same CV mortality reduction as those with established ASCVD yet no prior atherothrombotic event. ${ }^{60}$

In the DECLARE-TIMI 58 trial, patients with prior MI had an especially large benefit from dapagliflozin compared with subjects with no history of $\mathrm{MI}^{61}$ (MACE: prior MI adjusted risk ratio $[\mathrm{ARR}] 2.6 \%$; $\mathrm{HR}, 0.84 ; 95 \% \mathrm{CI}, 0.72-099$; no prior MI ARR 0\% HR, 1.00; 95\% CI, 0.81-1.19. Heart failure hospitalisation/CV mortality: prior MI ARR $1.9 \%$ HR, 0.81 ; 95\% CI, 0.65-1.00; no prior MI 0.6\%; HR, 0.85; 95\% CI, $0.72-1.00)$. Patients with known atherosclerotic CVD but no prior MI had a smaller benefit from dapagliflozin (ARR, $0.2 \%$; HR, 0.98; 95\% CI, 0.81-1.19) compared with individuals with a prior MI. There was a greater reduction of MACE in the 2 years after the last acute coronary event with no apparent reduction of MACE if the MI occurred more than 36 months after treatment initiation. Similar reductions of heart failure hospitalisation and of the renal composite endpoint were observed in patients with and without a history of MI. The magnitude of the risk reduction for recurrent CVD events with an SGLT2 inhibitor is similar to that observed with other CV protective treatments such as statins or anti-platelet agents. 
The Dapagliflozin (DAPA) Heart Failure study showed that patients with heart failure (with $44 \%$ having a history of MI) with or without diabetes had $26 \%$ reduced combined CV events (CV death, hospitalisation for HF, or urgent $\mathrm{HF}$ visit HR, 0.74; 95\% CI, 0.65-0.85). CV death was reduced $18 \%$.

Clinical trials with the 7 GLP-1 RA that are published or top-line results reported show heterogeneity in $\mathrm{CV}$ outcomes. Four fully reported studies, Liraglutide Effect and Action in Diabetes: Evaluation of Cardiovascular Outcome Results (LEADER) $^{62}$ with liraglutide, Trial to Evaluate Cardiovascular and Other Long-term Outcomes with Semaglutide in Subjects with Type 2 Diabetes 6 (SUSTAIN 6) ${ }^{63}$ with semaglutide, Researching Cardiovascular Events With a Weekly Incretin in Diabetes (REWIND) ${ }^{64}$ with dulaglutide and Albiglutide and cardiovascular outcomes in patients with type 2 diabetes and cardiovascular disease (Harmony Outcomes) ${ }^{65}$ with albiglutide show the GLP-1 RA reduced the primary MACE end point. In addition, the results of Peptide Innovation for Early Diabetes Treatment (PIONEER 6 ${ }^{66}$ ) suggests a cardiovascular benefit from oral semaglutide. Yet 2 other trials, the Evaluation of Lixisenatide in Acute Coronary Syndrome (ELIXA) (ELIXA) ${ }^{67}$ with lixisenatide and the Exenatide Study of Cardiovascular Event Lowering (EXSCEL) ${ }^{68}$ with once weekly exenatide, showed no reduction of the primary end points. Liraglutide in the LEADER trial resulted in a $22 \%$ reduction of CV mortality, whereas semaglutide in the SUSTAIN 6 trial reduced stroke but not CV mortality. A reduction of heart failure presentation is generally not seen with GLP-1 RA. In patients with and without a history of MI or stroke there was a consistent $\mathrm{CV}$ benefit with liraglutide. The impact on coronary and cerebrovascular events and the general lack of impact on heart failure suggest that the CV benefit of GLP-1 RA is likely a vascular protective benefit.

Serious adverse events from both SGLT2 inhibitors ${ }^{69}$ and GLP-1 RA ${ }^{70}$ are infrequent. SGLT2 inhibitors may cause superficial mycotic genital infections, urinary tract infections, diabetic ketoacidosis DKA (may occur with no hyperglycemia), and hypoglycemia (if used in a patient on insulin or a sulfonylurea). In the EMPA-REG Outcome trial, no increase in serious adverse events were reported. In the CANVAS trials, there was a small increase in adverse events due to volume depletion, yet acute kidney injury was not increased. No increase in volume depletion symptoms was observed in the other 3 trials including the CREDENCE trial with canagliflozin. A small increase in the incidence of diabetic ketoacidosis was observed in DECLARE-TIMI 58 and CREDENCE (2 vs 0.2 events/1000 patients/year). In the CANVAS study, there was a 2-fold increase in amputations: an adverse event that has not been observed in any other SGLT2 inhibitor study including the CREDENCE study. Genital infections with candida species were increased in all the clinical trials, yet they are usually no more than mild to moderate in severity, generally respond rapidly to oral or topical antifungal agents, and rarely result in discontinuation of the SGLT2 inhibitor.

Symptomatic volume depletion and hypotension can be minimised by identification of patients at risk and the adjustment of diuretics and other blood pressure-lowering agents including angiotensin-converting enzyme inhibitor inhibitors and ARBs. Hypoglycemia may be avoided by reducing or discontinuing sulfonylureas and making small adjustments to insulin dosage in patients at risk. Mycotic genital infections are probably reduced by good perineal hygiene and patient education. Diabetic ketoacidosis is usually associated with an intercurrent illness and instructing the patient to take a "sick day" temporary discontinuation of the SGLT2 inhibitor during an acute event or need for major surgery will reduce the risk.

The optimal timing to initiate an SGLT2 inhibitor in a patient with a recent ACS is unknown. None of the cardiovascular outcome trials with an SGLT2 inhibitor enrolled patients sooner than 2 months after the acute coronary event. However, the patient with type 2 diabetes and a recent ACS may benefit from early initiation of treatment. For patients who are hemodynamically stable with controlled or no heart failure, and normal blood pressure, it is likely that the benefits of the early initiation of a SGLT2 inhibitor prior to hospital discharge exceed the potential small risks.

GLP-1 RA have no apparent adverse cardiovascular effects. Heart rate is increased approximately 2 to 5 beats $/ \mathrm{min}$, and blood pressure reduced. Gastrointestinal adverse effects may limit their use. However, they are usually transient and can be minimised with a slow dose escalation, the consumption of several small meals each day, and avoidance of high fat foods.

Guidelines from Diabetes Canada, ${ }^{42}$ American Diabetes Association, ${ }^{71}$ American College of Cardiology, ${ }^{72}$ and the European Association for the Study of Diabetes ${ }^{3 / 3}$ recommend the prescription of a glucose-lowering agent with proven $\mathrm{CV}$ benefits in patients with type 2 diabetes and established ASCVD. Guidelines from $\mathrm{ADA}^{71}$ do not require the patient to have an $\mathrm{A} 1 \mathrm{C}$ above the target level and recommend for patients with a risk for heart failure or diabetic kidney disease, an SGLT2 inhibitor is preferable to a GLP1 agonist. Guidelines from the European Society of Cardiology ${ }^{7,75}$ and the Canadian Society of Cardiology ${ }^{76}$ recommend the prescription of an SGLT2 inhibitor to prevent heart failure in patients at risk. Now with the results of the DAPA HF study, dapagliflozin should be considered as part of the treatment of patients with heart failure whether or not they have diabetes.

Although we recognise that there are barriers to care due to differing provincial formulary coverage for SGLT2 inhibitors, GLP1 agonists and PCSK9 inhibitors, we believe that it is our role to promote the use of optimal treatments. However it is important that physicians select the highest risk patients (as discussed earlier) and have initiated maximally tolerated statin therapy and ezetimibe before considering the prescription of an PCSK9 inhibitors.

\section{Colchicine for the Reduction of CV Events}

Colchicine, an anti-inflammatory agent principally used in the management of acute gout, has been shown to reduce adverse CV outcomes in patients with a recent MI. The Colchicine Cardiovascular Outcomes Trial (COLCOT) trial $^{77}$ enrolled 4745 patients within 30 days of an acute MI and randomised their treatment to colchicine $0.5 \mathrm{mg}$ daily or placebo. After a follow-up of 22 months, the primary composite end point (CV death resuscitated cardiac arrest, MI, stroke, or urgent hospitalization for angina) was reduced $23 \%$ by colchicine (HR, 0.77; 0.61-0.96). The rates of CV death and MI were not reduced. Stroke and unstable angina hospitalisation were significantly reduced. Adverse events occurring more frequently in the colchicine treated patients 
included diarrhoea (9.7\% vs $8.9 \%)$ and pneumonia $(0.9 \%$ vs $0.4 \%)$. The trial had some methodological limitations with a high discontinuation rate, and $2.5 \%$ of patients lost to followup. The primary end point is driven by hospitalisation for angina and revascularisation and not by important end points such as CV death or MI. Consequently, it is not possible to make any recommendations about the use of colchicine for $\mathrm{CV}$ protection without more robust data. ${ }^{78}$

\section{Conclusions}

Patients with a recent ACS provide an opportunity to initiate and optimise multifaceted strategies to reduce the high risk of recurrent CVD events. Evidence-based recommendations from clinical guidelines support lifestyle modifications (including smoking cessation, weight optimisation, healthy diet, and physical activity) and the use of ASA, statins, angiotensin-converting enzyme inhibitor inhibitors or ARBs, blood pressure control, and glycemic control. These were discussed in the prior publication and are summarised in Figure 1. Extended treatment with antiplatelet agents and the use of anticoagulants provide a strategy to reduce recurrent ACS and CV mortality in patients with increased CV risk yet with a lower threat of bleeding. PCSK9 inhibitors added to statin treatment provides additional reduction of CV event rates and can be considered in patients with very high CV risk or not achieving LDL-C targets despite maximally tolerated statin and ezetimibe treatment. Icosapent ethyl in patients with elevated triglycerides despite LDL-C-lowering therapy leads to significant reductions in CV event rates. Both SGLT2 inhibitors and GLP1-RA reduce CV events (including CV mortality) and should be considered for cardiovascular protection in patients with diabetes and prior MI whatever the A1C.

\section{Disclosures}

David H. Fitchett: Speaker/Consulting honoraria: Amgen, AstraZeneca, Boehringer Ingelheim, Eli Lilly, Janssen, Sanofi, and Servier. Steering committee for EMPA-REG Outcomes, Data Safety Monitoring Boards for Novo Nordisk.

Jennifer Pickering: Speaker/Consulting honoraria: AstraZeneca, Bristol-Myers Squibb, Pfizer, and Sanofi.

Lawrence A. Leiter: Research grant support or speaker/ consulting honoraria from Amgen, AstraZeneca, Bayer, Boehringer Ingelheim, Eli Lilly, Esperion, GlaxoSmithKline, HLS Therapeutics, Janssen, The Medicine Company, Merck, Novartis, Novo Nordisk, Sanofi, and Servier.

Jean Gregoire: Speaker/Consulting honoraria: Abbott, Amgen, AstraZeneca, Bayer, Boehringer Ingelheim, BristolMyers Squibb, Eli Lilly, Ferring Pharmaceuticals, HLS Therapeutics, Janssen/Johnson \& Johnson, Merck, Novartis, Novo Nordisk, Pfizer, Sanofi, and Servier.

Shaun G. Goodman: Research grant support (eg, steering committee or data and safety monitoring committee) or speaker/consulting honoraria (eg, advisory boards) from Amgen, AstraZeneca, Bayer, Boehringer Ingelheim, BristolMyers Squibb, CSL Behring, Daiichi-Sankyo/American Regent, Eli Lilly, Esperion, Ferring Pharmaceuticals, GlaxoSmithKline, HLS Therapeutics, Janssen/Johnson \& Johnson, Merck, Novartis, Novo Nordisk A/C, Pfizer, Regeneron,
Sanofi, and Servier; salary support from the Heart and Stroke Foundation of Ontario/University of Toronto (Polo) Chair, Canadian Heart Research Centre and MD Primer, Canadian VIGOUR Centre, Duke Clinical Research Institute, New York University Clinical Coordinating Centre, and PERFUSE Research Institute.

Robert Welsh: Research support: AstraZeneca, Bayer, Boehringer Ingelheim, and Pfizer. Honoraria: Bayer, BMS/ Pfizer, and Boehringer Ingelheim.

Peter Lin: Speaker Honoraria: AstraZeneca, Boehringer Ingelheim, Bayer, Amgen, Janssen, Merck, and Servier. Consultant/Advisory Board Honoraria: AstraZeneca, Boehringer Ingelheim, Bayer, Eli Lilly, Merck, Sanofi, and Amgen.

Anil Gupta: Advisory board/speaker for Amgen, AstraZeneca, Bayer, Boehringer Ingelheim, Bristol-Myers Squibb, Pfizer, and Sanofi.

Anatoly Langer: Research grant support from Actelion, Amgen, AstraZeneca, Bayer, Boehringer Ingelheim, BristolMyers Squibb, Janssen/Johnson \& Johnson, Merck, Novartis, Novo Nordisk Pfizer, Sanofi, Servier, and Valeant/Bausch.

Philip McFarlane: Research grant support or speaker/ consulting honoraria from AMGEN, AstraZeneca, Bayer, Bristol-Myers Squibb, Boehringer Ingelheim, GSK, Janssen, Lilly, Novartis Otsuka, Sanofi-Aventis, Servier, and Vifor.

James Stone: Consulting or Speaker honoraria for Amgen, HLS Therapeutics, Sanofi, AstraZeneca, Boehringer Ingelheim, Lilly, Novartis, Novo-Nordisk, and Servier.

\section{References}

1. Fitchett DH, Goodman SG, Leiter LA, et al. Secondary prevention beyond hospital discharge for acute coronary syndrome: evidence-based recommendations. Can J Cardiol 2016;32(7 Suppl):S15-34.

2. Yusuf S, Zhao F, Mehta SR, et al. Effects of clopidogrel in addition to aspirin in patients with acute coronary syndromes without ST-segment elevation. N Engl J Med 2001;345:494-502.

3. Wallentin L, Becker RC, Budaj A, et al. Ticagrelor versus clopidogrel in patients with acute coronary syndromes. N Engl J Med 2009;361: 1045-57.

4. Wiviott SD, Braunwald E, McCabe $\mathrm{CH}$, et al. Prasugrel versus clopidogrel in patients with acute coronary syndromes. N Engl J Med 2007;357:2001-15.

5. Hahn JY, Song YB, Oh JH, et al. 6-month versus 12-month or longer dual antiplatelet therapy after percutaneous coronary intervention in patients with acute coronary syndrome (SMART-DATE): a randomised, open-label, non-inferiority trial. Lancet 2018;391:1274-84.

6. Watanabe H, Kimura T. 1 vs 12 months of dual antiplatelet therapy for patients after percutaneous coronary intervention-reply. JAMA 2019;322: 1715-6.

7. Mehta SR, Bainey KR, Cantor WJ, et al. 2018 Canadian Cardiovascular Society/Canadian Association of Interventional Cardiology Focused Update of the Guidelines for the Use of Antiplatelet Therapy. Can J Cardiol 2018;34:214-33.

8. Vranckx P, Valgimigli M, Juni $P$, et al. Ticagrelor plus aspirin for 1 month, followed by ticagrelor monotherapy for 23 months vs aspirin plus clopidogrel or ticagrelor for 12 months, followed by aspirin monotherapy for 12 months after implantation of a drug-eluting stent: a multicentre, open-label, randomised superiority trial. Lancet 2018;392:940-9. 
9. Hahn JY, Song YB, Oh JH, et al. Effect of P2Y12 inhibitor monotherapy vs dual antiplatelet therapy on cardiovascular events in patients undergoing percutaneous coronary intervention: The SMART-CHOICE Randomized Clinical Trial. JAMA 2019;321:2428-37.

10. Mehran R, Baber U, Sharma SK, et al. Ticagrelor with or without aspirin in high-risk patients after PCI. N Engl J Med 2019;381:2032-42.

11. Hahn JY, Song YB, Gwon HC. P2Y12 inhibitor monotherapy vs dual antiplatelet therapy after percutaneous coronary intervention-reply. JAMA 2019;322:1607-8.

12. Bonaca MP, Bhatt DL, Cohen M, et al. Long-term use of ticagrelor in patients with prior myocardial infarction. N Engl J Med 2015;372: $1791-800$.

13. Bhatt DL, Bonaca MP, Bansilal S, et al. Reduction in ischemic events with ticagrelor in diabetic patients with prior myocardial infarction in PEGASUS-TIMI 54. J Am Coll Cardiol 2016;67:2732-40.

14. Magnani G, Storey RF, Steg G, et al. Efficacy and safety of ticagrelor for long-term secondary prevention of atherothrombotic events in relation to renal function: insights from the PEGASUS-TIMI 54 trial. Eur Heart J 2016;37:400-8.

15. Bonaca MP, Bhatt DL, Storey RF, et al. Ticagrelor for prevention of ischemic events after myocardial infarction in patients with peripheral artery disease. J Am Coll Cardiol 2016;67:2719-28.

16. Bansilal S, Bonaca MP, Cornel JH, et al. Ticagrelor for secondary prevention of atherothrombotic events in patients with multivessel coronary disease. J Am Coll Cardiol 2018;71:489-96.

17. Magnuson EA, Li H, Wang K, et al. Cost-Effectiveness of long-term ticagrelor in patients with prior myocardial infarction: results from the PEGASUS-TIMI 54 Trial. J Am Coll Cardiol 2017;70:527-38.

18. Eikelboom JW, Connolly SJ, Bosch J, et al. Rivaroxaban with or without aspirin in stable cardiovascular disease. N Engl J Med 2017;377:1319-30.

19. Sharma M, Hart RG, Connolly SJ, et al. Stroke outcomes in the COMPASS Trial. Circulation 2019;139:1134-45.

20. Eikelboom JW, Bosch JJ, Connolly SJ, et al. Major bleeding in patients with coronary or peripheral artery disease treated with rivaroxaban plus aspirin. J Am Coll Cardiol 2019;74:1519-28.

21. Anand SS, Bosch J, Eikelboom JW, et al. Rivaroxaban with or without aspirin in patients with stable peripheral or carotid artery disease: an international, randomised, double-blind, placebo-controlled trial. Lancet 2018;391:219-29.

22. Anand SS, Caron F, Eikelboom JW, et al. Major adverse limb events and mortality in patients with peripheral artery disease: The COMPASS Trial. J Am Coll Cardiol 2018;71:2306-15.

23. Connolly SJ, Eikelboom JW, Bosch J, et al. Rivaroxaban with or without aspirin in patients with stable coronary artery disease: an international, randomised, double-blind, placebo-controlled trial. Lancet 2018;391: 205-18.

24. Lamy A, Eikelboom J, Sheth T, et al. Rivaroxaban, aspirin, or both to prevent early coronary bypass graft occlusion: The COMPASS-CABG Study. J Am Coll Cardiol 2019;73:121-30.

25. Fox KAA, Eikelboom JW, Shestakovska O, et al. Rivaroxaban plus aspirin in patients with vascular disease and renal dysfunction: from the COMPASS Trial. J Am Coll Cardiol 2019;73:2243-50.

26. Mega JL, Braunwald E, Wiviott SD, et al. Rivaroxaban in patients with a recent acute coronary syndrome. N Engl J Med 2012;366:9-19.

27. Yeh RW, Secemsky EA, Kereiakes DJ, et al. Development and validation of a prediction rule for benefit and harm of dual antiplatelet therapy beyond 1 year after percutaneous coronary intervention. JAMA 2016;315:1735-49.

28. Baber U, Mehran R, Giustino G, et al. Coronary thrombosis and major bleeding after PCI with drug-eluting stents: risk scores from PARIS. J Am Coll Cardiol 2016;67:2224-34.

29. Costa F, van Klaveren D, James S, et al. Derivation and validation of the predicting bleeding complications in patients undergoing stent implantation and subsequent dual antiplatelet therapy (PRECISE-DAPT) score: a pooled analysis of individual-patient datasets from clinical trials. Lancet 2017;389:1025-34.

30. Pasea L, Chung SC, Pujades-Rodriguez M, et al. Personalising the decision for prolonged dual antiplatelet therapy: development, validation and potential impact of prognostic models for cardiovascular events and bleeding in myocardial infarction survivors. Eur Heart J 2017;38: 1048-55.

31. Ueda P, Jernberg T, James S, et al. External validation of the DAPT score in a nationwide population. J Am Coll Cardiol 2018;72:1069-78.

32. Lindholm D, Sarno G, Erlinge D, et al. Combined association of key risk factors on ischaemic outcomes and bleeding in patients with myocardial infarction. Heart 2019;105:1175-81.

33. Bonaca MP, Storey RF, Theroux P, et al. Efficacy and safety of ticagrelor over time in patients with prior MI in PEGASUS-TIMI 54. J Am Coll Cardiol 2017;70:1368-75.

34. Anderson TJ, Gregoire J, Pearson GJ, et al. 2016 Canadian Cardiovascular Society Guidelines for the Management of Dyslipidemia for the Prevention of Cardiovascular Disease in the Adult. Can J Cardiol 2016;32:1263-82.

35. Cannon $\mathrm{CP}$, Braunwald $\mathrm{E}, \mathrm{McCabe} \mathrm{CH}$, et al. Intensive versus moderate lipid lowering with statins after acute coronary syndromes. N Engl J Med 2004;350:1495-504.

36. Cannon CP, Blazing MA, Giugliano RP, et al. Ezetimibe added to statin therapy after acute coronary syndromes. N Engl J Med 2015;372: 2387-97.

37. Sabatine MS, Giugliano RP, Keech AC, et al. Evolocumab and clinical outcomes in patients with cardiovascular disease. N Engl J Med 2017;376:1713-22.

38. Schwartz GG, Steg PG, Szarek M, et al. Alirocumab and cardiovascular outcomes after acute coronary syndrome. N Engl J Med 2018;379: 2097-107.

39. Giugliano RP, Pedersen TR, Park JG, et al. Clinical efficacy and safety of achieving very low LDL-cholesterol concentrations with the PCSK9 inhibitor evolocumab: a prespecified secondary analysis of the FOURIER trial. Lancet 2017;390:1962-71.

40. Sabatine MS, De Ferrari GM, Giugliano RP, et al. Clinical benefit of evolocumab by severity and extent of coronary artery disease. Circulation 2018;138:756-66.

41. Sabatine MS, Leiter LA, Wiviott SD, et al. Cardiovascular safety and efficacy of the PCSK9 inhibitor evolocumab in patients with and without diabetes and the effect of evolocumab on glycaemia and risk of new-onset diabetes: a prespecified analysis of the FOURIER randomised controlled trial. Lancet Diabetes Endocrinol 2017;5:941-50.

42. Ray KK, Colhoun HM, Szarek M, et al. Effects of alirocumab on cardiovascular and metabolic outcomes after acute coronary syndrome in patients with or without diabetes: a prespecified analysis of the ODYSSEY OUTCOMES randomised controlled trial. Lancet Diabetes Endocrinol 2019;7:618-28. 
43. Bonaca MP, Nault P, Giugliano RP, et al. Low-density lipoprotein cholesterol lowering with evolocumab and outcomes in patients with peripheral artery disease: insights from the FOURIER Trial (Further Cardiovascular Outcomes Research With PCSK9 Inhibition in Subjects With Elevated Risk). Circulation 2018;137:338-50.

44. Jukema JW, Szarek M, Zijlstra LE, et al. Patients with recent acute coronary syndrome and polyvascular disease derive large absolute benefit from alirocumab: ODYSSEY OUTCOMES Trial. J Am Coll Cardiol 2019;74:1167-76.

45. Mach F, Baigent C, Catapano AL, et al. 2019 ESC/EAS Guidelines for the management of dyslipidaemias: lipid modification to reduce cardiovascular risk. Eur Heart J 2020;41:111-88.

46. Goodman SG, Aylward PE, Szarek M, et al. Effects of alirocumab on cardiovascular events after coronary bypass surgery. J Am Coll Cardiol 2019;74:1177-86.

47. Lawler PR, Kotrri G, Koh M, et al. Real-world risk of cardiovascular outcomes associated with hypertriglyceridaemia among individuals with atherosclerotic cardiovascular disease and potential eligibility for emerging therapies. Eur Heart J 2020;41:86-94.

48. Ganda OP, Bhatt DL, Mason RP, Miller M, Boden WE. Unmet need for adjunctive dyslipidemia therapy in hypertriglyceridemia management. J Am Coll Cardiol 2018;72:330-43.

49. Aung T, Halsey J, Kromhout D, et al. Associations of omega-3 fatty acid supplement use with cardiovascular disease risks: meta-analysis of 10 trials involving 77917 individuals. JAMA Cardiol 2018;3:225-34.

50. Yokoyama M, Origasa H, Matsuzaki M, et al. Effects of eicosapentaenoic acid on major coronary events in hypercholesterolaemic patients (JELIS): a randomised open-label, blinded endpoint analysis. Lancet 2007;369: 1090-8.

51. Bhatt DL, Steg PG, Miller M, et al. Cardiovascular risk reduction with icosapent ethyl for hypertriglyceridemia. N Engl J Med 2019;380:11-22.

52. Bhatt DL, Steg PG, Miller M, et al. Reduction in first and total ischemic events with icosapent ethyl across baseline triglyceride tertiles. J Am Coll Cardiol 2019;74:1159-61.

53. Bhatt DL, Steg PG, Miller M, et al. Effects of icosapent ethyl on total ischemic events: from REDUCE-IT. J Am Coll Cardiol 2019;73: 2791-802.

54. Zelniker TA, Wiviott SD, Raz I, et al. SGLT2 inhibitors for primary and secondary prevention of cardiovascular and renal outcomes in type 2 diabetes: a systematic review and meta-analysis of cardiovascular outcome trials. Lancet 2019;393:31-9.

55. Zelniker TA, Wiviott SD, Raz I, et al. Comparison of the effects of glucagon-like peptide receptor agonists and sodium-glucose cotransporter 2 inhibitors for prevention of major adverse cardiovascular and renal outcomes in type 2 diabetes mellitus. Circulation 2019;139:2022-31.

56. Zinman B, Wanner C, Lachin JM, et al. Empagliflozin, cardiovascular outcomes, and mortality in type 2 diabetes. N Engl J Med 2015;373: 2117-28.

57. Neal B, Perkovic V, Mahaffey KW, et al. Canagliflozin and cardiovascular and renal events in type 2 diabetes. N Engl J Med 2017;377: 644-57.

58. Wiviott SD, Raz I, Bonaca MP, et al. Dapagliflozin and cardiovascular outcomes in type 2 diabetes. N Engl J Med 2019;380:347-57.

59. Perkovic V, Jardine MJ, Neal B, et al. Canagliflozin and renal outcomes in type 2 diabetes and nephropathy. N Engl J Med 2019;380:2295-306.
60. Fitchett D, Inzucchi SE, Cannon CP, et al. Empagliflozin reduced mortality and hospitalization for heart failure across the spectrum of cardiovascular risk in the EMPA-REG OUTCOME Trial. Circulation 2019;139:1384-95.

61. Furtado RHM, Bonaca MP, Raz I, et al. Dapagliflozin and cardiovascular outcomes in patients with type 2 diabetes and prior myocardial infarction: a sub-analysis from DECLARE TIMI-58 Trial. Circulation 2019;139:2516-27.

62. Marso SP, Daniels GH, Brown-Frandsen K, et al. LEADER Steering Committee on behalf of the LEADER Trial Investigators. Liraglutide and cardiovascular outcomes in type 2 diabetes. N Engl J Med 2016;375: $311-22$.

63. Marso SP, Bain SC, Consoli A, et al. Semaglutide and cardiovascular outcomes in patients with type 2 diabetes. N Engl J Med 2016;375: $1834-44$.

64. Gerstein HC, Colhoun HM, Dagenais GR, et al. Dulaglutide and cardiovascular outcomes in type 2 diabetes (REWIND): a doubleblind, randomised placebo-controlled trial. Lancet 2019;394: $121-30$.

65. Hernandez AF, Green JB, Janmohamed S, et al. Albiglutide and cardiovascular outcomes in patients with type 2 diabetes and cardiovascular disease (Harmony Outcomes): a double-blind, randomised placebocontrolled trial. Lancet 2018;392:1519-29.

66. Husain M, Donsmark M, Bain SC. Oral semaglutide and cardiovascular outcomes in type 2 diabetes. Reply. N Engl J Med 2019;381:2076-7.

67. Pfeffer MA, Claggett B, Diaz R, et al. Lixisenatide in patients with type 2 diabetes and acute coronary syndrome. N Engl J Med 2015;373: 2247-57.

68. Holman RR, Bethel MA, Mentz RJ, et al. Effects of once-weekly exenatide on cardiovascular outcomes in type 2 diabetes. N Engl J Med 2017;377:1228-39.

69. Fitchett D. A safety update on sodium glucose co-transporter 2 inhibitors. Diabetes Obes Metab 2019;21(Suppl 2):34-42.

70. Prasad-Reddy L, Isaacs D. A clinical review of GLP-1 receptor agonists: efficacy and safety in diabetes and beyond. Drugs Context 2015;4: 212283.

71. Pharmacologic approaches to glycemic treatment: standards of medical care in diabetes. Diabetes Care 2019;42(Suppl 1):S90-102.

72. Das SR, Everett BM, Birtcher KK, et al. 2018 ACC Expert Consensus Decision Pathway on Novel Therapies for Cardiovascular Risk Reduction in Patients With Type 2 Diabetes and Atherosclerotic Cardiovascular Disease: A Report of the American College of Cardiology Task Force on Expert Consensus Decision Pathways. J Am Coll Cardiol 2018;72: 3200-23.

73. Davies MJ, D’Alessio DA, Fradkin J, et al. Management of hyperglycemia in type 2 diabetes, 2018. a consensus report by the American Diabetes Association (ADA) and the European Association for the Study of Diabetes (EASD). Diabetes Care 2018;41: 2669-701.

74. Piepoli MF, Hoes AW, Agewall S, et al. 2016 European Guidelines on cardiovascular disease prevention in clinical practice: The Sixth Joint Task Force of the European Society of Cardiology and Other Societies on Cardiovascular Disease Prevention in Clinical Practice (constituted by representatives of 10 societies and by invited experts) Developed with the special contribution of the European Association 
for Cardiovascular Prevention \& Rehabilitation (EACPR). Eur Heart J 2016;37:2315-81.

75. Ponikowski P, Voors AA, Anker SD, et al. 2016 ESC Guidelines for the diagnosis and treatment of acute and chronic heart failure: The Task Force for the diagnosis and treatment of acute and chronic heart failure of the European Society of Cardiology (ESC). Developed with the special contribution of the Heart Failure Association (HFA) of the ESC. Eur J Heart Fail 2016;18:891-975.
76. Ezekowitz JA, O’Meara E, McDonald MA, et al. 2017 Comprehensive Update of the Canadian Cardiovascular Society Guidelines for the Management of Heart Failure. Can J Cardiol 2017;33:1342-433.

77. Tardif JC, Kouz S, Waters DD, et al. Efficacy and safety of low-dose colchicine after myocardial infarction. N Engl J Med 2019;381: 2497-505.

78. Newby LK. Inflammation as a treatment target after acute myocardial infarction. N Engl J Med 2019;381:2562-3. 